P18 (continued)

behaviors. Highly active individuals reported significantly greater FV intake $(2.7 \pm .1)$ than moderately active $(2.1 \pm .1)$ or inactive $(1.6 \pm .3)$. FV intake was greater in those reporting meal preparation 4-7 times weekly $(3.1 \pm .2)$ compared to $1-3(2.4 \pm .1)$ or zero times weekly $(2.3 \pm .1)$. Cooking mostly convenience and ready-made meals was associated with significantly lower FV intake $(2.1 \pm .1)$ compared to preparing meals from basic ingredients $(2.6 \pm .2)$ or not cooking (2.5 \pm .1$)$. Intention for $\mathrm{MP}$ and mealtime behaviors were positively associated with FV intake. Preparing meals from basic ingredients was associated with a lower BMI (23.8 \pm .3$)$ than consuming mostly convenience and ready-made meals

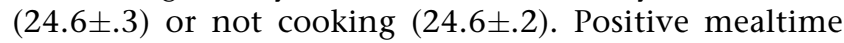
behaviors were inversely related to BMI.

Conclusions and Implications: FV intake and BMI are influenced by PA, cooking, and dietary behaviors. Although many interventions for college students focus on PA and diet, programs should consider including a cooking focus. Funding: USDA

\section{P19 Appalachian Young Adults Food Security and Tobacco Use}

Rachel A. Wattick, West Virginia University;

Makenzie Barr, BS; Rebecca L. Hagedorn, BS;

Karla Shelnutt, PhD, RDN, University of Florida;

Anne Mathews, PhD, RDN; Sarah E. Colby, PhD, RDN, University of Tennessee; Melissa D. Olfert, DPH, DrPH, RDN, melissa.olfert@mail.wvu.edu, West Virginia University, 333 AG SC Building G28, Morgantown, WV 26506

Objective: To examine the relationship between tobacco use and food security of young adults in the Appalachian region.

Study Design, Setting, Participants: Data was analyzed from the Fruved study, a social marketing campaign increasing healthier lifestyles among college students from eight universities across the United States who were assessed at baseline (Fall 2015) (N=347).

Outcome Measures and Analysis: Food security was scored using the USDA Adult Food Security Survey. Participants were asked about the frequency of their use of tobacco products (cigarettes, hookah/waterpipe, electronic cigarettes, cigars/cigarillos, pipe, chew, snuff, and snus) within their lifetime, the past year, and the past 30 days. Food security status, tobacco use, and geographical regions were compared.

Results: Fourty-three percent $(\mathrm{N}=301)$ of non-Appalachian students and 50\% (N=44) of Appalachian students were categorized as food insecure $(\mathrm{p}=0.44) .63 .6 \%$ of respondents $(\mathrm{N}=345)$ reported using tobacco in their lifetime, $11.5 \%$ in the past year, and $37.9 \%$ in the past thirty days. No significant difference was found in relationship between all food security and tobacco use (tobacco in lifetime $\mathrm{p}=0.47$; tobacco in last year $\mathrm{p}=0.42$; tobacco in last 30 days $\mathrm{p}=0.92$ ). Furthermore, no significant difference was found in Appalachian vs Non-Appalachian groups for tobacco use in any category $(\mathrm{p}=0.52, \mathrm{p}=0.67$, $\mathrm{p}=0.65$, respectively).

Conclusion and Implications: Geographical location can be a determinant of behavior. In this study no difference in comparison of frequency of tobacco use among Appalachia students and other regions were found. However, this study was limited by a small sample of Appalachian young adults. Future research is warranted to investigate food security and tobacco use as well as other commonly abused substances.

Funding: USDA; WVU Hatch Experimental Station

\section{P20 Associations Between Variables of the Home Food Environment and Fruit and Vegetable Intake in College Students}

Abeer Almudaihim, MS, University of Florida; Anne Mathews, PhD, RD; Melissa Vilaro, PhD; Shannon Gordon, BS; Karla Shelnutt, PhD, RD, kpagan@ufl. edu, University of Florida, 3028 McCarty Hall D, Gainesville, FL 32611

Objective: To determine which variables within three domains of the comprehensive home food environment (Home Food Availability and Cues; College Student Food Practice; Social Support and Modeling) are associated with fruit and vegetable (FV) intake of college students.

Study Design, Setting, Participants: Baseline survey data from the Healthy Home Study, a subproject of the Get FRUVED Study, were collected online during Fall 2016 from new freshmen $(n=157 ; 18$ to 25 years $)$ at the University of Florida. Participants were recruited through Get FRUVED and list servs, lived on campus, and stored food at their dorm. Participants received $\$ 20$ for completing surveys.

Outcome Measures and Analysis: Participants completed the Comprehensive Home Food Environment Survey, Dietary Screener Questionnaire, demographic questionnaire, and Social Support and Eating Habits Survey. A spearman correlation analysis was used to test for basic association between each variable of the home food environment and FV intake. Variables that significantly correlated with FV intake were included in a multiple regression analysis.

Results: A multiple linear regression was calculated to predict [FV consumption] based on [variables within three domains of the comprehensive home food environment]. A significant regression equation was found $(\mathrm{F}(3,154)=14.9, \mathrm{p}<.000)$, with an R2 of .225]. Preliminary data suggest that availability of FV at home, healthy food preparation skills, and screen viewing were significant predictors of FV intake $(\beta=0.302$; $\mathrm{p}<.01, \beta=0.235 ; \mathrm{p}<.01$ and $\beta=-0.203 ; \mathrm{p}<.03$, respectively).

Conclusions and Implications: This study identified modifiable factors within the home food environment associated with FV intake, which have been targeted in 